\title{
Outcomes of primary anal sphincter repair after obstetric injury and evaluation of a novel three-choice assessment
}

\author{
K. Kuismanen ${ }^{1,2} \cdot$ K. Nieminen ${ }^{1} \cdot$ K. Karjalainen ${ }^{3} \cdot K$ Lehto $^{2,4} \cdot$ J. Uotila $^{1}$
}

Received: 15 February 2017 / Accepted: 15 January 2018 / Published online: 15 March 2018

(c) The Author(s) 2018

\begin{abstract}
Background The aim of the present study was to evaluate the subjective outcome of primary repair of obstetric anal sphincter injury (OASIS) at 6 months, the factors associated with the symptoms of anal incontinence (AI), and the role of a simple survey consisting in one question with three answer choices, combined with the Wexner incontinence score for the assessment of this patient population.

Methods A retrospective cohort study was conducted on patients with third- or fourth-degree OASIS operated on between January 2007 and December 2013 inclusive at Tampere University Hospital, Finland. At 6 months, the patients were asked to report their Wexner's score as well as the three-choice assessment regarding AI symptoms. Based on this assessment, the patients were divided into three groups: those, asymptomatic, those with mild symptoms who did not want further treatment and those with severe symptoms who were willing to undergo further evaluation and treatment.

Results There were 325 patients (median age 30 years). A total of 310 patients answered the questionnaire. Of which, one hundred and ninety-eight (63.9\%) patients were asymptomatic, 85 (27.4\%) had mild AI, and 27 (8.7\%) experienced severe symptoms. There was no statistical difference in the results between the two techniques used (overlapping vs. end-to-end), or the stage of specialization of the operating physician. Persistent symptoms were associated with instrumental vaginal delivery (OR 2.12, 95\% CI 1.32-3.41), severity of the injury (OR 1.64, 95\% CI 1.20-2.25), and increased maternal age (OR 1.07, 95\% CI 1.02-1.13). The correlation between the three-choice symptom evaluation and the Wexner score was good (Spearman's rho 0.82).

Conclusions After 6 months, severe symptoms after OASIS repair were present in 9\% of women and were more frequent in older women, women with high-degree tears and after instrumental vaginal delivery. A three-choice assessment of AI symptoms correlated well with the Wexner score and might be useful to triage patients who need further evaluation.
\end{abstract}

Keywords Anal sphincter $\cdot$ Anal incontinence $\cdot$ Fecal incontinence $\cdot$ Obstetric anal sphincter injury

\section{Introduction}

Anal incontinence (AI) is defined by involuntary loss of feces or flatus [1]. The most common traumatic cause for AI in women is obstetric anal sphincter injury (OASIS) [2]. The

\footnotetext{
K. Kuismanen

kirsi.kuismanen@pshp.fi

1 Department of Obstetrics and Gynecology, Tampere University Hospital, Tampere, Finland

2 Faculty of Medicine and Life Sciences, University of Tampere, Tampere, Finland

3 National Institute for Health and Welfare, Helsinki, Finland

4 Department of Gastroenterology and Alimentary Tract Surgery, Tampere University Hospital, Tampere, Finland
}

incidence of obstetric third- and fourth-degree anal sphincter rupture varies from approximately $11 \%$ [3] worldwide to $0.6-4.2 \%$ in Nordic countries [4]. Known risk factors for OASIS are high fetal birth weight, long duration of second stage of delivery, operative delivery, primiparity, and midline episiotomy [5, 6].

AI despite primary OASIS repair has been reported to occur in $61 \%$ of patients [7]. The extent of sphincter damage [8], operative vaginal delivery [9], older age, and high body mass index (BMI) [10] are associated with the risk of fecal incontinence after primary repair.

In Finland, extensive and continuous efforts have been made to prevent OASIS and to improve the quality of diagnostics and repair [11].There has also been discussion about the optimal specialization (gynecologist or colorectal surgeon) of the operating physician and surgical team [12]. 
Outcomes after OASIS have improved with time, and the symptoms of anal incontinence are reported less frequently than previously [7].

The aim of this study was to examine the subjective outcome of OASIS primary repair surgery and to recognize the factors associated with persistent AI symptoms. We also evaluated the role of a simple three-choice assessment combined with the Wexner incontinence score [13] in patients with OASIS.

\section{Materials and methods}

A retrospective cohort study on women with OASIS was conducted between January 2007 and December 2013 inclusive at Tampere University Hospital, Finland, a tertiary care teaching hospital with up to 5400 deliveries per year. The yearly cesarean section rate varied between $14.6 \%$ (2012) and $17.7 \%$ (2007), and the rate of operative vaginal deliveries from $5.6 \%$ (2013) to $8.1 \%$ (2008). At our hospital, the perineum is supported to prevent perineal tears in almost all deliveries [11]. According to the classification of OASIS, a third-degree injury involves the anal sphincters; (3a) involves less than $50 \%$ of thickness of the external anal sphincter, (3b) more than $50 \%$ of thickness of the external anal sphincter, and (3c) both the external and internal anal sphincter. Fourth-degree injury extends to the anorectal mucosa [14]. Our initial analysis was made of patients diagnosed with all types of third-degree injuries as well as fourth-degree obstetric anal sphincter injuries. Recurrent anal sphincter injuries (three cases, recurrence rate $5 \%$ of attempted vaginal deliveries) were excluded from the analysis.

At 6 months, the patients were sent a questionnaire about subjective AI symptoms including a Wexner incontinence score sheet and a three-choice assessment form. The Wexner incontinence score contains questions about the frequency and type of incontinence or discomfort (solid stool, liquid stool, flatulence; the use of diapers or pads, lifestyle changes). A score of 0 corresponds with full continence, while a score of 20 corresponds with total incontinence [13]. The empirically developed assessment asking patients which of three answer choices best described their condition is: (1) the patient is satisfied and has no symptoms (=no symptoms); (2) has mild symptoms but does not wish for a doctor's appointment (=mild symptoms); and (3) has severe symptoms and wants to be contacted by a colorectal surgeon (=severe symptoms). This has been used to target the resources for women who want further treatment. The patients who reported severe symptoms were examined by a colorectal surgeon with endoanal ultrasound and anal manometry. A follow-up visit was arranged within 7-14 months of the initial injury.

In order to examine the variables associated with persistent AI among patients diagnosed with third- and fourthdegree obstetric anal injuries, the women were divided into two groups based on the three-choice assessment: those who reported no AI symptoms at 6 months after OASIS $(n=198)$, and those who had minor or severe symptoms $(n=112)$. The study population is described in Fig. 1. The groups were compared using pre-labor and intrapartum factors.

\section{Statistical analysis}

Statistical significance was tested by using Pearson's Chisquare test with categorical and one-way analysis of variance (ANOVA) with continuous variables. Spearman's rank correlation test was used to analyze the correlation between the Wexner incontinence score and the subjective outcome measure. The associations between different explanatory

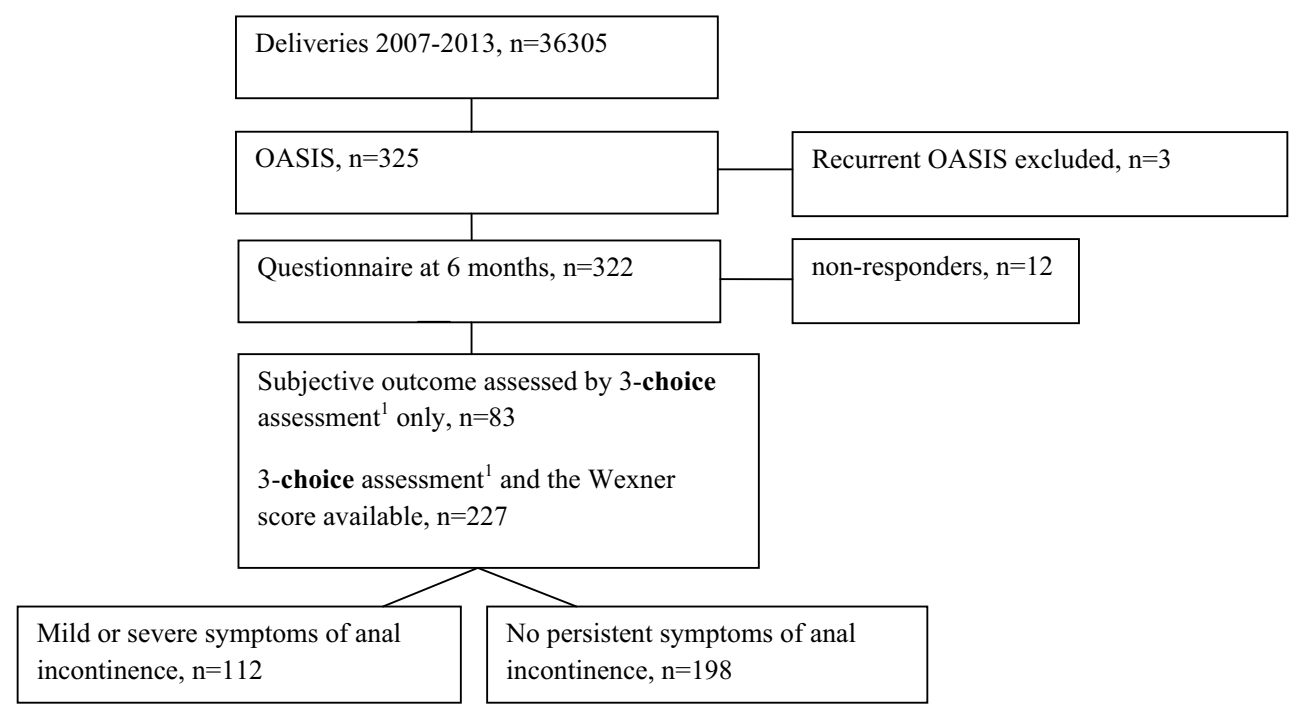

Fig. 1 The patient flow chart 
variables (Table 1) and the severity of symptoms were estimated by a logistic regression model, and the results were presented as odds ratios (OR) with $95 \%$ confidence intervals (CI). To distinguish between the asymptomatic and symptomatic groups, the severity of the anal incontinence symptoms $(0=$ no symptoms, $1=\mathrm{mild} / \mathrm{severe}$ symptoms $)$ was used as an outcome variable. In addition to univariate analysis, the models were adjusted for clinically valid variables, such as age, BMI, parity, and mode of delivery. A $p$ value of $<0.05$ was considered statistically significant. The data analysis was performed using IBM SPSS 22 software (Chicago, IL, USA).

\section{Results}

Three hundred and twenty-five patients were diagnosed with OASIS between the start of 2007 and the end of 2013 from a total of 36,305 deliveries. Primiparas accounted for $42.4 \%$ of in the total number of obstetric patients, but
$76.6 \%$ of those who had OASIS. One hundred and ninetyfour patients with OASIS $(60.2 \%)$ had a spontaneous vaginal delivery (1 breech presentation), whereas 128 (39.8\%) had an instrumentally assisted delivery (vacuum: 127, forceps: 1). A mediolateral episiotomy was performed in 188 (58.4\%) cases), which differs from the total annual episiotomy rate in the hospital of 20-26\% during the study period. The annual incidence of OASIS ranged from 0.69 to $1.10 \%$.

All patients were operated on within $24 \mathrm{~h}$ of the delivery by either a resident, specialized gynecologist, or a colorectal surgeon. During their hospital stay, the patients received prophylactic antibiotics and had physiotherapy counseling including perineal inspection, pelvic floor exercise instructions as well as dietary information. The physiotherapist examined the patients and their pelvic floor function 3 months after the delivery.

Most of the patients had stage $3 \mathrm{a}(44.8 \%)$ or $3 \mathrm{~b}(41.6 \%)$ tears, $11.6 \%$ had $3 \mathrm{c}$, and only six patients $(1.9 \%)$ had a stage 4 rupture. Sixty-five doctors were involved in the operations either operating or assisting, and the operation volumes per

Table 1 The demographic and clinical characteristics of the study groups

\begin{tabular}{|c|c|c|c|c|c|}
\hline & $\begin{array}{l}\text { No symptoms } \\
n=198\end{array}$ & $\begin{array}{l}\text { Mild or severe } \\
\text { symptoms } \\
n=85+27=112\end{array}$ & $p$ & $\begin{array}{l}\text { Univariate model } \\
\text { OR }(95 \% \mathrm{CI})\end{array}$ & $\begin{array}{l}\text { Multivariate } \\
\text { model }^{\mathrm{a}} \text { OR }(95 \% \\
\mathrm{CI})\end{array}$ \\
\hline Age (years) & $29.0(\mathrm{SD} 4.5)$ & 30.5 (SD 4.9) & 0.015 & & \\
\hline Age $>30$ & $76(38.4 \%)$ & $59(52.7 \%)$ & 0.007 & $1.79(1.12-2.86)$ & $1.75(1.07-2.86)$ \\
\hline $\mathrm{BMI}\left(\mathrm{kg} / \mathrm{m}^{2}\right)$ & $24.1(\mathrm{SD} 4.6)$ & $23.8($ SD 3.9) & 0.456 & & \\
\hline $\mathrm{BMI}>30$ & $21(10.6 \%)$ & $8(7.1 \%)$ & 0.314 & $0.65(0.28-1.52)$ & $0.67(0.28-1.60)$ \\
\hline Induction of labor & $37(18.7 \%)$ & $28(25.0 \%)$ & 0.190 & $1.45(0.83-2.53)$ & $1.36(0.76-2.43)$ \\
\hline Oxytocin for augmentation & $162(81.8 \%)$ & $94(83.8 \%)$ & 0.638 & $1.16(0.62-2.16)$ & $0.90(0.47-1.73)$ \\
\hline \multicolumn{6}{|l|}{ Duration of 2 stage } \\
\hline$\leq 5 \mathrm{~min}$ & $6(3.0 \%)$ & $5(4.5 \%)$ & 0.017 & $1.97(0.58-6.73)$ & $2.06(0.55-7.72)$ \\
\hline $5.01-44.99 \mathrm{~min}(\mathrm{ref})$ & $130(65.7 \%)$ & $55(49.1 \%)$ & & 1 & 1 \\
\hline$\geq 45 \mathrm{~min}$ & $62(31.3 \%)$ & $52(46.4 \%)$ & & $1.98(1.22-3.22)$ & $1.41(0.82-2.42)$ \\
\hline Episiotomy & $107(54.0 \%)$ & $73(65.2 \%)$ & 0.056 & $1.59(0.99-2.57)$ & $1.23(0.71-2.23)$ \\
\hline Epidural analgesia & $138(69.7 \%)$ & $77(68.8 \%)$ & 0.862 & $0.96(0.58-1.58)$ & $0.81(0.48-1.39)$ \\
\hline Spinal analgesia & $17(8.6 \%)$ & $8(7.1 \%)$ & 0.654 & $0.82(0.34-1.96)$ & $0.77(0.30-1.98)$ \\
\hline Birthweight (grams) & $3742(\mathrm{SD} 493)$ & 3704 (SD 480) & 0.515 & & \\
\hline weight $>4 \mathrm{~kg}$ & $50(25.3 \%)$ & $31(27.7 \%)$ & 0.640 & $1.13(0.67-1.91)$ & $1.23(0.71-2.14)$ \\
\hline Head circumference mean $\mathrm{cm}$ & $35.6(\mathrm{SD} 1.4)$ & $35.3(\mathrm{SD} 1.5)$ & 0.117 & & \\
\hline Occipitoposterior position & $21(10.6 \%)$ & $21(18.8 \%)$ & 0.044 & $1.95(1.01-3.75)$ & $1.81(0.91-3.61)$ \\
\hline Instrumental delivery & $65(32.8 \%)$ & $57(50.9 \%)$ & 0.002 & $2.12(1.32-3.41)$ & $2.06(1.26-3.36)$ \\
\hline \multicolumn{6}{|l|}{ Classification of injury } \\
\hline $3 a(r e f)$ & $100(50.5 \%)$ & $39(34.8 \%)$ & 0.008 & $1.91(1.18-3.08)$ & $1.92(1.17-3.15)$ \\
\hline $3 \mathrm{~b} / \mathrm{c} / 4$ & $98(49.5 \%)$ & $73(65.2 \%)$ & & & \\
\hline Operation technique end-to-end (ref overlapping) & $123(62.1 \%)$ & $58(51.8 \%)$ & 0.076 & $0.66(0.41-1.05)$ & $0.86^{\mathrm{b}}(0.50-1.50)$ \\
\hline Operated by a resident alone (ref specialist) & $42(21.2 \%)$ & $17(15.2 \%)$ & 0.194 & $0.67(0.36-1.23)$ & $0.69(0.36-1.30)$ \\
\hline
\end{tabular}

Statistically significant $p$ values are shown in bold

Data presented as mean (SD) or $n(\%)$

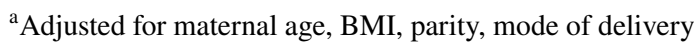

${ }^{\mathrm{b}}$ Also adjusted for classification of injury 
doctor varied from 1 single assisted operation to 31 performed operations. The operative technique was overlapping for $134(41.2 \%)$ and end-to end for 191 (58.8\%) patients, according to the operating surgeon's preference. The endto-end technique was used mostly (92.6\%) for stage $3 \mathrm{a}$ or $3 \mathrm{~b}$ ruptures, and all of the stage 4 ruptures were treated using the overlapping technique.

\section{Anal incontinence symptoms}

According to the three-choice assessment, 198 (63.9\%) women reported no symptoms at 6 months after OASIS repair and did not wish for an appointment with a doctor. Mild symptoms without need for a visit were reported by $85(27.4 \%)$ women. Severe symptoms were reported by 27 (8.7\%) women.

As shown in Table 1 (univariate model), advanced maternal age, long duration of the second stage of the delivery, occipitoposterior presentation, instrumental delivery, severe type of injury, and hospital stay of over 4 days were all associated with poorer outcomes at 6 months. However, in the multivariate model, only instrumental vaginal delivery, severe injury, and advanced maternal age persisted in being associated factors. Neither the operative technique nor the experience or specialization of the operating physician (resident gynecologist, specialist in gynecology or colorectal surgeon) was associated with poor outcome. The milder $3 \mathrm{a}$ tears were more often managed by a resident $(34.5 \%$ of all 3a tears), whereas all the grade 4 tears were operated on by a senior gynecologist. Only $26(8.1 \%)$ of the anal sphincter ruptures were operated on by a colorectal surgeon. Three out of $27(11 \%)$ patients with persistent severe symptoms had a second sphincter repair operation. One of the patients regained anal continence after the operation, while two remained incontinent. Most of the remaining 24 patients received extended pelvic floor physiotherapy and were satisfied with the results.

\section{Wexner incontinence score}

The Wexner incontinence score was returned by 227 patients (70.1\% of the total study population). The Wexner incontinence score was 0-4 for 193 (59.9\%) patients, 5-6 for 17 (5.3\%), and $\geq 7$ for 17 (5.3\%) patients. In the asymptomatic group, the Wexner score was 0-4 for 120 patients (99.2\%), while 22 patients $(81.5 \%)$ of those with severe symptoms had a Wexner score of 5 or higher. However, there was some discrepancy between the Wexner score and the patients' perception of the severity of their symptoms; in the asymptomatic group, the Wexner incontinence score ranged from 0 to 9 , and in the mildly or severely dissatisfied groups from 2 to 14 . Nevertheless, the three-choice assessment and the
Wexner incontinence score showed significant correlation (Spearman's rho 0.82) (Fig. 2).

\section{Discussion}

The overall short-term subjective results of OASIS primary repair were encouraging. However, $9 \%$ of the patients had severe symptoms at 6 months. This is similar to results of other studies, although other studies do not take into account subjective patient factors [15].

We found the grading of the injury to be an important prognostic factor. This finding supports that of Roos et al., where patients with grade $3 \mathrm{c}-4$ injuries had a significantly poorer outcome than those with grade $3 a-b$ injuries based on quality of life and the results of anal manometry. Women with major tears were also significantly more likely to have an internal and external anal sphincter defect detectable by endosonography [16].

Instrumental vaginal delivery was independently associated with AI at 6 months after primary sphincter repair. Johannessen et al. [17] discovered the occipitoposterior presentation to be the only prognostic factor for AI in primiparas. However, in our study, the association between the occipitoposterior position and AI disappeared after adjusting for maternal age, BMI, parity, and mode of delivery in multivariate logistic regression analysis. Neither was the duration of the second stage of delivery a prognostic factor for poor outcome. A mediolateral episiotomy has been considered as a protective factor from OASIS [18], but, in our study, the episiotomy did not seem to have an effect on AI symptoms after primary repair.

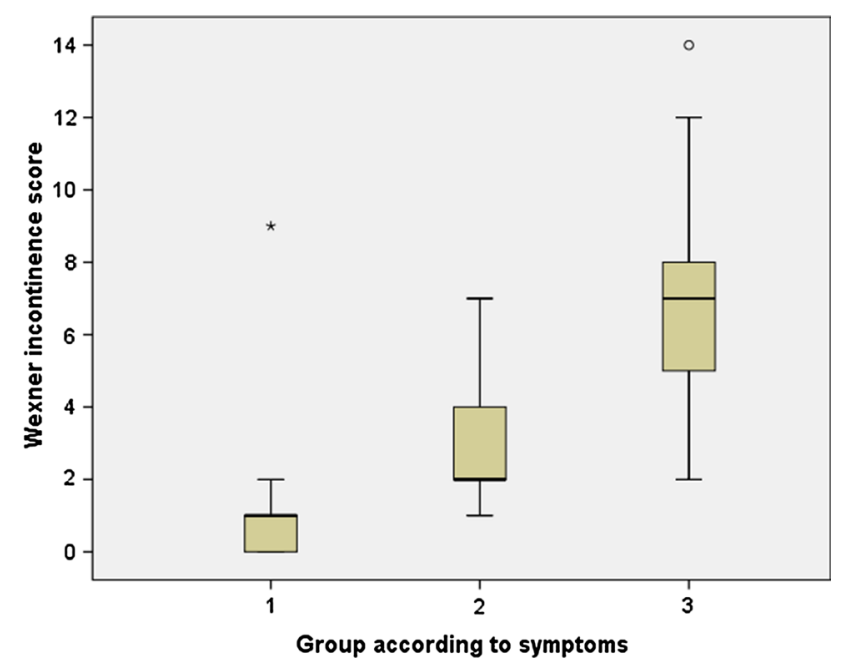

Fig. 2 The correlation between the Wexner incontinence score and the three-choice assessment 
There was no statistical difference between the two repair techniques at 6 months. This is in contrast with some studies that found the overlapping technique was superior according to the symptoms at 12 months [19]. However, the milder ruptures were more often repaired using the end-to-end technique and the more severe ruptures with overlapping. The specialization or seniority of the surgeon did not seem to affect the results, although there was probably bias due to differences in assessment of the severity of the injury. The crucial step in OASIS treatment may be the recognition, and the operative technique seems to be less important.

The Wexner incontinence score is a simple and well established grading system [20]. The Wexner score of 9 has been considered a threshold for severe AI with significant impairment of the quality of life associate with scores higher than this [21]. Our study showed that patients with a Wexner score of 5 or higher reported severe symptoms. Therefore, a Wexner score of 4 might be a suitable threshold for further examinations to detect poor responders after primary repair in OASIS patients (young, previously healthy women). Additionally, in our study population, a simple three-choice assessment was very informative, as the correlation between the three-choice assessment and the Wexner score was good. The three-choice assessment takes the patient's desire for further action into consideration and is informative especially when combined with the Wexner score. A visual analog scale (VAS) has also been used together with St Mark's score to detect women who are troubled by AI [22]. Devesa et al. did not find sufficient agreement between the Wexner score and VAS and did not recommend the replacement of the validated AI scores [23]. In our opinion, the three-choice assessment might be a useful addition to current assessment methods.

The incidence of OASIS remained low during the study period, in contrast to some reports from Australia [24] and the UK [25]. The low incidence in Finland might be due to the practice of manually supporting the perineum when the baby's head is crowning through the vaginal introitus [11]. In Israel, the incidence of OASIS has remained low, in spite of increased detection rate, due to the incorporation of manual perineal protection, the avoidance of midline episiotomy and the fact that the use of forceps is almost extinct [26]. In our study population, the recurrence rate of OASIS was 5\%, which was similar to previous findings [27].

The long-term outcome of anal sphincter repair has to be further investigated. Farrell et al. found in their randomized trial comparing operative techniques that 39\% (end-to-end) to $61 \%$ (overlapping) of primiparas suffered from flatus incontinence at 6 months, and at 3 years, flatus incontinence still bothered 39 and $43 \%$ of women, respectively [28]. In a Dutch cohort study, the women with OASIS had more than double the risk of long-term troublesome AI compared with the control group after a 4-year follow-up [29].
There are still women who need alternative treatment methods after OASIS primary repair. Secondary sphincteroplasty may not have the desired results, as the women often have denervated sphincters [30]. Sacral nerve modulation, as well as transcutaneous posterior tibial neuromodulation, has successfully been used for fecal incontinence, although follow-up times have been short [31]. Tissue engineering and stem cell therapy are future options and open new possibilities for the restoration of both the anatomy and function of the anal sphincter muscle [32-34].

This study reflects the usual practice in a large teaching hospital where over 60 doctors operated on OASIS patients during the study period. That outcome seems unrelated to specialty or experience deems not to support concentration of repair to the hands of a few.

Among the strengths of the study are the low drop-out volume, and the fact that a single center study enables thorough checking of every patient file to guarantee accurate classification of data. Our results reflect the patient's own perception of the problem and the desire for further action, which might help in targeting health care resources. One limitation of the study is that not all patients returned the questionnaire and the Wexner score was missing in $27 \%$ of the cases. Other limitations are the retrospective nature of the study, as well as the lack of objective measurements (ultrasound, physical examination) of all the patients. Additionally, the three-choice assessment was not validated.

\section{Conclusions}

Six months after delivery severe symptoms after OASIS repair were present in $9 \%$ of women. In addition to the Wexner score, a simple three-choice assessment of anal incontinence symptoms might be useful for evaluating the results of anal sphincter primary repair in OASIS patients and to survey the patient's desire for further procedures.

\section{Compliance with ethical standards}

Conflict of interest The authors declare that they have no conflict of interest.

Ethical approval The study was approved by the Tampere University Hospital Science center according to the Finnish legislation and Helsinki declaration.

Informed consent For this type of study, formal consent is not required.

Open Access This article is distributed under the terms of the Creative Commons Attribution 4.0 International License (http://creativeco mmons.org/licenses/by/4.0/), which permits unrestricted use, distribution, and reproduction in any medium, provided you give appropriate credit to the original author(s) and the source, provide a link to the Creative Commons license, and indicate if changes were made. 


\section{References}

1. Haylen BT, de Ridder D, Freeman RM et al (2010) An international urogynecological association (IUGA)/international continence society (ICS) joint report on the terminology for female pelvic floor dysfunction. Int Urogynecol J 21(1):5-26

2. Sultan AH, Kamm MA, Hudson CN, Thomas JM, Bartram CI (1993) Anal-sphincter disruption during vaginal delivery. N Engl J Med 329(26):1905-1911. https://doi.org/10.1056/NEJM199312 233292601

3. Dudding TC, Vaizey CJ, Kamm MA (2008) Obstetric anal sphincter injury: incidence, risk factors, and management. Ann Surg 247(2):224-237. https://doi.org/10.1097/SLA.0b013e318142cdf4

4. Laine K, Gissler M, Pirhonen J (2009) Changing incidence of anal sphincter tears in four nordic countries through the last decades. Eur J Obst Gynecol 146(1):71-75. https://doi.org/10.1016/j.ejogr b.2009.04.033

5. de Leeuw JW, Struijk PC, Vierhout ME, Wallenburg HCS (2001) Risk factors for third degree perineal ruptures during delivery. $\mathrm{Br}$ J Obstet Gynaecol 108(4):383-387. https://doi.org/10.1016/S0306 -5456(00)00090-5

6. Stedenfeldt M, Pirhonen J, Blix E, Wilsgaard T, Vonen B, Oian P (2012) Episiotomy characteristics and risks for obstetric anal sphincter injuries: a case-control study. BJOG 119(6):724-730. https://doi.org/10.1111/j.1471-0528.2012.03293.x

7. Pinta TM, Kylänpää M, Salmi TK, Teramo KAW, Luukkonen PS (2004) Primary sphincter repair: are the results of the operation good enough? Dis Colon Rect 47(1):18-23. https://doi. org/10.1007/s10350-003-0006-9

8. de Leeuw JW, Vierhout ME, Struijk PC, Hop WCJ, Wallenburg HCS (2001) Anal sphincter damage after vaginal delivery: functional outcome and risk factors for fecal incontinence. Acta Obstet Gynecol Scand 80(9):830-834. https://doi.org/10.103 4/j.1600-0412.2001.080009830.x

9. Huebner M, Gramlich NK, Rothmund R, Nappi L, Abele H, Becker S (2013) Fecal incontinence after obstetric anal sphincter injuries. Int J Gynecol Obstet 121(1):74-77. https://doi. org/10.1016/j.ijgo.2012.10.023

10. Burgio KL (2007) Risk factors for fecal and urinary incontinence after childbirth: the childbirth and pelvic symptoms study. Am J Gastroenterol 102(9):1998-2004. https://doi.org/10.111 1/j.1572-0241.2007.01364.x

11. Pirhonen J, Grenman S, Haadem K et al (1998) Frequency of anal sphincter rupture at delivery in Sweden and Finlandresult of difference in manual help to the babys head. Acta Obstet Gynecol Scand 77(10):974-977. https://doi.org/10.103 4/j.1600-0412.1998.771005.x

12. McNicol FJ, Bruce CA, Chaudhri S et al (2010) Management of obstetric anal sphincter injuries-a role for the colorectal surgeon. Colorectal Dis 12(9):927-930. https://doi.org/10.111 $1 / \mathrm{j} .1463-1318.2009 .01897 . x$

13. Jorge JM, Wexner SD (1993) Etiology and management of fecal incontinence. Dis Colon Rectum 36(1):77-97

14. Thiagamoorthy G, Johnson A, Thakar R, Sultan A (2014) National survey of perineal trauma and its subsequent management in the United Kingdom. Int Urogynecol J 25(12):1621-1627. https://doi. org/10.1007/s00192-014-2406-x

15. Ramalingam K, Monga A (2013) Outcomes and follow-up after obstetric anal sphincter injuries. Int Urogynecol J 24(9):14951500. https://doi.org/10.1007/s00192-013-2051-9

16. Roos AM, Thakar R, Sultan AH (2010) Outcome of primary repair of obstetric anal sphincter injuries (OASIS): Does the grade of tear matter? Ultrasound Obstet Gynecol 36(3):368-374

17. Johannessen HH, Wibe A, Stordahl A, Sandvik L, Morkved S (2015) Anal incontinence among first time mothers-What happens in pregnancy and the first year after delivery? Acta Obstet Gynecol Scand 94(9):1005-1013

18. Verghese T, Champaneria R, Kapoor D, Latthe P (2016) Obstetric anal sphincter injuries after episiotomy: systematic review and meta-analysis. Int Urogynecol J 27(10):1459-1467. https://doi. org/10.1007/s00192-016-2956-1

19. Fernando RJ, Sultan AH, Kettle C, Thakar R (2013) Methods of repair for obstetric anal sphincter injury. Cochrane Database Syst Rev 12:CD002866. https://doi.org/10.1002/14651858.CD002866. pub3

20. Vaizey CJ, Carapeti E, Cahill JA, Kamm MA (1999) Prospective comparison of faecal incontinence grading systems. Gut 44(1):77-80

21. Rothbarth J, Bemelman WA, Meijerink WJ et al (2001) What is the impact of fecal incontinence on quality of life? Dis Colon Rectum 44(1):67-71

22. Paka C, Atan IK, Dietz HP (2016) The bother of anal incontinence and St. Mark's incontinence score. Tech Coloproctol 20(2):123128. https://doi.org/10.1007/s10151-015-1397-z

23. Devesa JM, Vicente R, Abraira V (2013) Visual analogue scales for grading faecal incontinence and quality of life: their relationship with the Jorge-Wexner score and Rockwood scale. Tech Coloproctol 17(1):67-71. https://doi.org/10.1007/s10151-012-0884-8

24. Ampt AJ, Patterson JA, Roberts CL, Ford JB (2015) Obstetric anal sphincter injury rates among primiparous women with different modes of vaginal delivery. Int J Gynaecol Obstet 131(3):260-264

25. Gurol-Urganci I, Cromwell DA, Edozien LC et al (2013) Thirdand fourth-degree perineal tears among primiparous women in England between 2000 and 2012: time trends and risk factors. BJOG 120(12):1516-1525

26. Ginath S, Mizrachi Y, Bar J, Condrea A, Kovo M (2017) Obstetric anal sphincter injuries (OASIs) in Israel: a review of the incidence and risk factors. Rambam Maimonides Med J. https://doi. org/10.5041/RMMJ.10295

27. Boggs EW, Berger H, Urquia M, McDermott CD (2014) Recurrence of obstetric third-degree and fourth-degree anal sphincter injuries. Obstet Gynecol 124(6):1128-1134

28. Farrell SA, Flowerdew G, Gilmour D et al (2012) Overlapping compared with end-to-end repair of complete third-degree or fourth-degree obstetric tears: three-year follow-up of a randomized controlled trial. Obstet Gynecol 120(4):803-808

29. Cornelisse S, Arendsen LP, van Kuijk SM, Kluivers KB, van Dillen J, Weemhoff M (2016) Obstetric anal sphincter injury: a follow-up questionnaire study on longer-term outcomes. Int Urogynecol J 27(10):1591-1596

30. Pescatori LC, Pescatori M (2014) Sphincteroplasty for anal incontinence. Gastroenterol Rep (Oxf) 2(2):92-97

31. Thin NN, Taylor SJ, Bremner SA et al (2015) Randomized clinical trial of sacral versus percutaneous tibial nerve stimulation in patients with faecal incontinence. Br J Surg 102(4):349-358

32. Frudinger A, Kölle D, Schwaiger W, Pfeifer J, Paede J, Halligan S (2010) Muscle-derived cell injection to treat anal incontinence due to obstetric trauma: pilot study with 1 year follow-up. Gut 59(1):55. https://doi.org/10.1136/gut.2009.181347

33. Frudinger A, Pfeifer J, Paede J, Kolovetsiou-Kreiner V, Marksteiner R, Halligan S (2015) Autologous skeletal-muscle-derived cell injection for anal incontinence due to obstetric trauma: a 5 -year follow-up of an initial study of 10 patients. Colorectal Dis 17(9):794-801. https://doi.org/10.1111/codi.12947

34. Fitzwater JL, Grande KB, Sailors JL, Acevedo JF, Word RA, Wai CY (2015) Effect of myogenic stem cells on the integrity and histomorphology of repaired transected external anal sphincter. Int Urogynecol J 26(2):251-256 